\title{
Adana ve çevresindeki kronik immün trombositopenik purpura'lı hastalarda Helicobacter pylori birlikteliğinin ve eradikasyonunun değerlendirilmesi
}

\author{
Kadir Eser¹, İsmail Fikri Başlamışlı² \\ ${ }^{1}$ Mersin Üniversitesi Tıp Fakültesi İç Hastalıkları AD Tıbbi Onkoloji Bilim Dalı. Mersin \\ ${ }^{2}$ Çukurova Üniversitesi Tıp Fakültesi İç Hastalıkları AD Hematoloji Bilim Dalı
}

\section{Öz}

Amaç: İmmün Trombositopenik Purpura'lı hastalarda platelet sayısını yükselterek tedaviye yardımcı olmak. İmmun Trombositopenik Purpura etyopatogenezinin tam olarak bilinememesi ve mevcut tedavi yöntemlerinin yan etkilerinin ağırlığı ve başarısının istenen ölçüde olmaması nedeni ile yeni çalışma, araștırma ve tedavi yöntemlerine ihtiyaç duyulmaktadır. Helikobakter Pylori'nin immün sistem etkisi bilindiğinden, İmmün Trombositopenik Purpura'lı hastalarda eradike edilmesi, pratik uygulamalarda seçilmiş hastalarda rutin olarak uygulanırsa hastaların tedavilerine ve yaşam kalitelerine katkı sağlaması yanında pahalı tedavilerin kullanımını da azaltabilir. Yöntem: Bu çalışmaya Kronik İmmün Trombositopenik Purpura nedeni ile takip edilen ve daha önce yapılmış olan tedavi veya tedavilere rağmen trombosit düzeyi 80 binin altında olan hastalar alınmıştır. Çalıșmaya 12'si erkek 26'sı kadın 38 İmmün Trombositopenik Purpura'lı hasta alındı ve 14C'lu Üre Nefes Testi uygulandı. Üre Nefes Testi ile Helikobakter Pylori enfeksiyonu saptanan hastalara iki hafta eradikasyon tedavisi verdikten sonra dört hafta beklendi ve Üre Nefes Testi tekrarland. Eğer Helikobakter Pylori eradike edilememişse ikinci basamak eradikasyon tedavisi yine iki hafta verildi ve tedavi bittikten dört hafta sonra tekrar Üre Nefes Testi yapıldı ve dört haftada bir trombosit sayısı takibi yapıldı. Bulgular: Çalışmaya alınan İmmün Trombositopenik Purpura'lı hastaların 23'ünde (\%60.5) Helikobakter Pylori saptandı. 23 İmmün Trombositopenik Purpura'lı enfekte hastaya eradikasyon tedavisi verildi ve 17 hastada (\%74) klasik üçlü tedavi rejimi ile Helikobakter Pylori eradikasyonu başarıldı. İkinci basamak, dörtlü rejimle de iki hastada daha eradikasyon sağlanarak toplam 19 hastada (\%82.6) Helikobakter Pylori eradikasyonu sağlanmış oldu. Sonrasında Helikobakter Pylori eradike edilen 19 hastanın üçünde (\%15.7) eradikasyon sonucu belirgin ve kalıcı trombosit sayısı artışı sağlanmıştır. Sonuçlar: İmmün Trombositopenik Purpura hastalarında Helikobakter Pylori eradikasyonu halen standart bir tedavi yaklaşımı olmamasına rağmen eradikasyon tedavisine belirgin cevap oranı olduğunu gösterdiğimiz çalışmamız en azından seçilmiş olgularda bu tedavinin yapılması fikrini desteklemektedir.

Anahtar sözcükler: Helikobakter pylori, immün trombositopenik purpura, üre nefes testi

Yazının geliş tarihi: 10.08 .2018

Yazının kabul tarihi: 11.10 .2018

Sorumlu Yazar: Kadir Eser Mersin Üniversitesi Çiftlikköy Kampüsü,Tıp Fakültesi İç Hastalıkları Anabilim Dalı, Tıbbi Onkoloji Bilim Dalı Yenișehir/Mersin

Tel: 05059125520

E-posta: drkadireser@gmail.com 


\title{
Researcing the coexistence and eradication of Helicobacter pylori in patients with chronic ITP around Adana
}

\begin{abstract}
Aims: To assist the treatment by increasing platelet count in patients with Immun Thrombocytopenic Purpura. New studies, research and treatment methods are needed due to the lack of knowledge about the etiopathogenesis of Immun Thrombocytopenic Purpura and the weight of treatment side effects and failure of current treatment methods. Helicobacter Pylori's immune system effect is known thus, eradication of Helicobacter Pylori in patients with Immun Thrombocytopenic Purpura may reduce the use of expensive therapies as well as contributing to the treatment of patients if applied routinely in selected patients in practical applications. Methods: This study was performed on patient with chronic Immun Thrombocytopenic Purpura who has $<80.000$ platelet levels despite previous treatments and include 38 patients with Immun Thrombocytopenic Purpura, consist of 12 male, 26 female patients. Urea Breath Test was made to all patients. Patients has Helicobacter Pylori enfection which is diagnosed with Urea Breath Test, after two weeks eradication treatment, control Urea Breath Test was repeated at sixth week. When Helicobacter Pylori wasn't eradicated, second line eradication therapy was prescribed two weeks and after 4 weeks end of the treatment Urea Breath Test was repeated. After the eradication platelet count was periodically measured. Results: The prevelance of Helicobacter Pylori, who has Immun Thrombocytopenic Purpura, is \%60 (23 patients with Immun Thrombocytopenic Purpura have infection with Helicobacter Pylori in 38 patient with H.Pylori). Eradication treatment was prescribed 23 patients with Immun Thrombocytopenic Purpura who have Helicobacter Pylori infection so, in 17 patients eradication was successed with classic tripple therapy, in 2 patients second line quadry therapy was prescribed and eradication was successed. With these regimens eradication rate was $82.6 \%$. Then, $3(15.7 \%)$ of 19 patients who were eradicated with H.Pylori had a significant and permanent increase in the number of platelets. Copnclusion: Although H.Pylori eradication in ITP patients is not a standard treatment approach, our study showing that there is a significant response rate to eradication treatment supports at least the idea of this treatment prescribing in selected cases.
\end{abstract}

Key words: Helicobacter pylori, immun thrombocytopenic purpura, urea breath test

\section{Giriş}

Helikobakter Pylori (H.Pylori) spiral şekilli, gram negatif, hareketli bir bakteridir, üreaz pozitifliği yaşamı ve kolonizasyonu için büyük bir öneme sahiptir. H. Pylori'nin şimdiye kadar gastrointestinal sistem ve gastrointestinal sistem dışı birçok hastalıkla ilişkili olduğu ve olabileceği ile ilgili çalışmalar gün geçtikçe artmaktadır. $H$. Pylori'nin gastrointestinal sistemde kronik gastrit ve peptik ülserin nedenlerinden olduğu ve mide kanseri ile MALT Lenfoma (mukoza ilişkili lenfoid doku lenfoması)'nın risk faktörlerinden biri olduğu açık bir şekilde bilinmektedir. Ekstraintestinal olarak ise $H$. Pylori'nin demir eksikliği nedenlerinden biri olduğu bilinmektedir. Son zamanlarda yapılan çalışmalarla da $H$. Pylori'nin İmmün Trombositopenik Purpura
(ITP)'nin etyolojisinde rol oynayan faktörlerden biri olabileceği açılanmaya çalışılmaktadır. ${ }^{1}$ Her iki hastalığın patogenezinde benzer mekanizmalarm olması nedeni ile iki hastalık arasında ilişki kurulmuştur. H.Pylori'nin eradike edilmesiyle erken dönem MALT Lenfoma'nın tedavi edilebilmesi lenfoid doku üzerine, dolayısıyla da immün sistem üzerine ne kadar etkili olabileceğini göstermiştir. ITP'nin patogenezinde de en önemli mekanizma olarak immün regülasyon mekanizmalarındaki bozukluğun suçlanması nedeni ile benzerlik kurulmuştur.,2,-5 H.Pylori'nin ITP'li hastalarda eradike edilmesi, pratik uygulamalarda seçilmiş hastalarda rutin olarak uygulanırsa hastaların tedavilerine ve yaşam kalitelerine katkı sağlaması 
yanında pahalı tedavilerin kullanımını da azaltabilir. Amacımı İmmün Trombositopenik Purpura (ITP)'ll hastalarda platelet sayısını yükselterek tedaviye yardımcı olmaktır.

\section{Yöntem}

Bu çalışmaya Çukurova Üniversitesi Tıp Fakültesi Dahiliye Hematoloji Polikliniği'nde Kronik ITP nedeni ile takip edilen ve daha önce yapılmış olan tedavi veya tedavilere rağmen trombosit düzeyi 80 binin altında olan hastalar, Ocak 2010 ve Aralık 2010 tarihleri arasında alınmıştır. Hastalar Adana ve çevre illerinden yani Çukurova Bölgesi'nden, Çukurova Üniversitesi Tıp Fakültesi Dahiliye Hematoloji Polikliniği'nde takip ve tedavi edilen hastalardır. Kronik ITP tanısı konulması için, ITP teşhisi konduktan sonra en az 12 ay geçmiş olması gerekiyordu. Hastalarda enfeksiyon ( $H I V, H C V)$, Sistemik Lupus Eritematozus (SLE), Kronik Lenfositik Lösemi (KLL), ilaç ilişkili, kronik karaciğer hastalığl, gebeliğin indüklediği trombositopeni gibi sekonder nedenler dışlandı. ${ }^{6}$ Hastaların 60 yaşından büyük olanlara ITP tanısı kemik iliği aspirasyon ve biyopsisi yapılarak, 60 yaşından küçük olanlara ise klinik ve fizik muayene bulguları, gerekirse kemik iliği aspirasyon ve biopsisi yapilarak tanı konuldu. Ancak tanıda şüphe edilen hastalardan yaşa bakılmaksızın kemik iliği aspirasyonu ve biopsisi yapıldı. Gebeliği bulunan, emziren kadınlar, 18 yaşından küçükler ve bilgilendirilmiş onam formunu imzalamayan hastalar çalışmaya alınmadı. Çalışmamız için etik kurul onayı alındı.

ITP'li tüm hastalar çalışmaya alınırken ve takip edilirken şu kriterlere uyuldu; 18 yaşından büyük olma, trombosit sayısının 80 binin altında olması, HIV-HCV enfeksiyonunun bulunmaması, ITP tanısı konulduktan sonra en az 12 ay geçmiş olması, hastanın son dört hafta içinde immünsupresif tedavi almamış olması veya alıyorsa son dört haftadır sabit dozda olması. Takip sırasında çok düşük trombosit sayısı ( $<10$ bin), 3.- 4. derece kanama semptomları varsa, programlı invaziv bir işlem uygulanması gerekiyorsa kurtarıcı tedavi olarak intravenöz immünglobülin tedavisi uygulanması planlandı. Hastaların son iki yll içinde H.Pylori eradikasyon tedavisi almadığına ve son dört hafta içinde proton pompa inhibitörü, antibiyotik veya bizmut tedavisi almadığına dikkat edildi.

Kriterlere uygun hastalara H.Pylori teşhisinde noninvaziv yöntemler içinde en duyarlı ve özgül yöntem olan Üre Nefes Testi (UBT) uyguland. UBT'de C13 ve C14 olmak üzere iki yöntemle yapılabilmektedir. C13 yöntemi radyoaktif açıdan hiçbir risk taşımaması yönünden avantajlı ancak maliyeti yüksek olması nedeni ile dezavantajlıdır. C14 yöntemi ise normal bir insanın yaşamında bir günde maruz kaldığı radyasyon miktarı kadar çok düşük radyoaktif özellik gösterebilir (gebeler ve çocuklar hariç kullanımı güvenli), maliyeti C13'e göre düşük olduğu için avantajlıdır. Biz çalışmamızda İsveç'te Kibion tarafından üretilen Heliprobe System C14 UBT kullandık. UBT yapmak için hastanın en az 8 saatlik aç olması, son dört haftadır antibiotik ve son iki haftadır proton pompa inhibitörü kullanmaması gerekmektedir. $\mathrm{Bu}$ şartlara uyan hastalara kapsül formatındaki C14'lü üre, $50 \mathrm{ml} \mathrm{su}$ ile birlikte verilir ve midede H.Pylori varsa üreaz enzimi ile üre, amonyak ve CO2'ye çevrilir. Buradaki CO2 C14'le işaretlidir ve akciğerlerden 10 dakika içinde atılır. Hastaların nefesleri bu radyoaktif C14'ü tutan bir kartuş içine solutulur, yeterli süreden sonra bu kartuş C14 düzeyi saptayan cihazda okutulur ve sonuçta <50DPM seviyesi H.Pylori negatif, 50-199 DPM seviyesi şüpheli, >200 DPM pozitiftir. Şüpheli sonuç gelen hastalara iki hafta sonra aynı test tekrar yapilır.

H.Pylori ile enfeksiyon saptanan hastalara iki hafta eradikasyon tedavisi verdikten sonra dört hafta bekleniyor ve UBT tekrarlaniyor. Eğer H.Pylori eradike edilememişse ikinci basamak eradikasyon tedavisi yine iki hafta veriliyor ve tedavi bittikten dört hafta sonra tekrar UBT yapilıyor.

H.Pylori ile enfekte ITP'li hastalara son zamanlarda yapılan çalışmalarda sıklıkla kullanılan Lansaprazol günde bir kez $30 \mathrm{mg} /$ gün, Amoksisilin iki eşit dozda verilme şekliyle 2000 mg/gün, Klaritromisin 
iki eşit dozda verilme șekliyle $1000 \mathrm{mg}$ /gün, iki hafta boyunca verildi. Hastalarda bu tedavi ile H.Pylori eradike edilemediği zaman Bizmut dört eşit dozda verilme şekliyle $1200 \mathrm{mg} /$ gün, Tetrasiklin dört eşit dozda verilme şekliyle $2000 \mathrm{mg} /$ gün, Metranidazol dört eşit dozda verilme

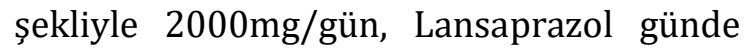
bir kez $30 \mathrm{mg}$ /gün iki hafta boyunca verildi. Bununla da eradike edilemeyenlerde H.Pylori dirençli kabul edildi ve Gastroenteroloji Bölümü'ne yönlendirildi.

Hastaların ilk trombosit sayısı UBT yapıldığı gün bakıldı, sonraki takiplerinde ilk sekiz hafta iki haftada bir, sonraki 16 hafta dört haftada bir, sonrasında da sekiz haftada bir bakıldı.

H.Pylori eradikasyon tedavisine cevaplılık ve cevapsızlık şöyle tanımlandı;

Tam cevap: tedaviden sonraki en az üç aylık süre sonunda normal trombosit düzeylerine ulaşma $(>150$ bin $)$ ve sonrasinda bu seviyede kalma.

Parsiyel cevap: Ulaşlan trombosit sayısı 149 binden az, 40 binlik artıştan fazla olmak şartıyla iki katlık artış ve sonrasında bu seviyede kalma.

Cevapsızlık: Trombosit sayısı artışı 40 binden fazla değil. (Trombosit sayısı 2 katına çıkmış olsa bile 40 binden fazla artış yoksa cevapsızlık sayıldı.)
Verilerin istatistiksel analizinde SPSS 17.0 paket programı kullanıldı. Kategorik ölçümler sayı ve yüzde olarak, sürekli ölçümlerse ortalama ve standart sapma olarak özetlendi. Kategorik ölçümlerin gruplar arasında karşılaştırılmasında Ki Kare test istatistiği kullanıldı. Gruplar arasında sürekli ölçümlerin karşılaştırılmasında Bağımsız gruplarda t testi kullanıldı. Tüm testlerde istatistiksel önem düzeyi 0.05 olarak alındı.

\section{Bulgular}

Klinik veriler 38 hastayı kapsamaktadır. Hastaların 12'si (\%31.5) erkeklerden, 26'sı (\%68.5) kadınlardan oluşmaktadır. Ortalama yaș; erkeklerde 45.2 16.6 (min:25, max:76), kadinlarda $41.0 \pm 12.6$ (aralı;;18-64). İki grup arasında istatistiksel olarak anlamlı fark saptanmadı ( $\mathrm{p}=0.215)$. Çalışmaya alınan ITP'li hastaların 23'ünde (\%60.5) H.Pylori saptand. H.Pylori enfeksiyonu prevelansı ITP'li erkeklerde 12 'de 9 (\%75), kadınlarda 26'da 14 (\%53.8) aralarında istatistiksel olarak anlaml fark bulunmadı $(\mathrm{p}=0.215)$. H.Pylori başlangıç durumu ile cinsiyet arasındaki ilişki ve hastaların cinsiyete göre dağılımı Tablo 1 de sunulmuştur.

Tablo 1. H.Pylori başlangıç durumu ile cinsiyet arasındaki ilişki

HelicobacterPylori Başlangıç Durumu

\begin{tabular}{|c|c|c|c|c|c|c|c|}
\hline & \multicolumn{2}{|c|}{ (-) Olanlar } & \multicolumn{2}{|c|}{$(+)$ Olanlar } & \multicolumn{2}{|c|}{ Toplam } & \multirow[t]{2}{*}{$\mathrm{P}$} \\
\hline & $n=15$ & $\%$ & $\mathrm{n}=23$ & $\%$ & $\mathrm{n}=38$ & $\%$ & \\
\hline Erkek & 3 & 20 & 9 & 39.1 & 12 & 31.5 & \\
\hline Kadın & 12 & 80 & 14 & 60.9 & 26 & 68.5 & 0.215 \\
\hline Toplam & 15 & 39.5 & 23 & 60.5 & 38 & 100.0 & \\
\hline
\end{tabular}


Hastaların 30'unun (\%78.9) daha önce ITP tedavisi aldığı tespit edilmiştir 23 hasta sadece steroid tedavisi, iki hasta steroid+ IVIG tedavisi, beş hasta steroid+ splenektomi tedavisi görmüştür. sekiz hasta hiçbir tedavi almamıştır, ilaçsız takip edilmektedir. Daha önce tedavi gören hastalar önceki tedavilere dirençli veya steroid bağımlılardır. Daha önce tedavi görmüş hastalarla tedavi görmemiş hastalar arasında H.Pylori açısından istatistiksel olarak anlamlı fark saptanmadı $(\mathrm{p}=0.493)$. H.Pylori bașlangıç durumu ile önceden tedavi öyküsü olup olmaması arasındaki ilişki Tablo 2'de sunulmuștur.

Ortalama trombosit sayısı takibi $30.7 \pm 11.5$ hafta (16-48 hafta arasında değişir). Takip süresi boyunca hiçbir hastada ITP ilişkili veya ilişkisiz ölüm görülmedi.

Bazal trombosit sayısı enfekte hastalarda 44.2 $\pm 17.5 \mathrm{bin}$, enfekte olmayan hastalarda $31.5 \pm 21.6$ bin olarak tespit edildi. H.Pylori ile enfekte ITP'li hastalarda bazal trombosit sayısı istatistiksel olarak anlamlı düzeyde daha yüksekti $(\mathrm{p}=0.039)$.

Başlangıç trombosit değerinin artışının değerlendirilmesi eradikasyon tedavisi bittikten iki hafta sonra yapıldı.

Takip sonunda H.Pylori eradike edilen 19 hastanın üçünde (\%15.7) eradikasyon sonucu belirgin ve kalıcl trombosit sayısı artıșı sağlanmıștır. Bir hastada tam cevap ve iki hastada da parsiyel cevap elde edilmiștir. Hastalardan ikisinde eradikasyon tedavisi bitiminden iki hafta sonra, birinde 20 hafta sonra cevap elde edilmiştir. Bu hastalardan başka iki hastada daha eradikasyondan sonra birinde ikinci haftada, diğerinde 10. haftada parsiyel trombosit cevabı olușmasına rağmen ilk hastada 32. haftada, diğerinde 16 . haftada relaps geliști. Bu relaps gelișen hastalara 48. haftada H.pylori testi tekrarlandı ve iki hastada da H.Pylori negatif olarak saptandl.

Tablo 2. H.Pylori başlangıç durumu ile önceden tedavi öyküsü olup olmaması arasındaki ilişki

\begin{tabular}{|c|c|c|c|c|c|c|c|}
\hline & \multicolumn{7}{|c|}{ Helicobacter Pylori Başlangıç Durumu } \\
\hline & \multicolumn{2}{|c|}{$(-)$ Olanlar } & \multicolumn{2}{|c|}{ (+) Olanlar } & \multicolumn{2}{|c|}{ Toplam } & \multirow[t]{2}{*}{$\mathrm{P}$} \\
\hline & $\mathrm{n}=15$ & $\%$ & $\mathrm{n}=23$ & $\%$ & $\mathrm{n}$ & $\%$ & \\
\hline $\begin{array}{l}\text { ITP Tedavi öyküsü } \\
\text { olanlar }\end{array}$ & 11 & 73.3 & 19 & 82.6 & 30 & 79.0 & \multirow{2}{*}{0.493} \\
\hline $\begin{array}{l}\text { ITP Tedavi öyküsü } \\
\text { olmayanlar }\end{array}$ & 4 & 26.7 & 4 & 17.4 & 8 & 21.0 & \\
\hline Toplam & 15 & 39.5 & 23 & 60.5 & 38 & 100.0 & \\
\hline
\end{tabular}

Eradikasyon tedavisi verilen ITP'li hastalardan, tedaviye cevaplı kabul edilen hastalar ortalama $22.6 \pm 8.3$ hafta (aralık 1632 hafta), tedaviye cevapsiz ancak H.Pylori eradike edilmiş hastalar $32.2 \pm 11.6$ hafta (aralık 16-48 hafta) takip edildi. Aralarında istatistiksel olarak anlaml fark yoktu ( $\mathrm{p}=0.195)$ (Tablo 3).

Eradikasyon tedavisine dirençli dört hastada takip sırasında cevap görülmedi.

Bazal trombosit sayısı 50 binin üstünde olan hastalarda kalıcı cevap oranı
\%14.2 (yedi hastanın biri, bu da parsiyel cevaptır). Bazal trombosit sayısı 30-50 bin arası olan hastalarda cevap oranı \%0 (8 hastada 0). Bazal trombosit sayısı 30 binin altında olan dört hastanın ikisi kalıcı cevap verdi, bunların da biri tam cevap, biri parsiyel cevaptır.

Hastalıksız sağkalım H.Pylori pozitif ITP'li hastalarda (eradikasyona cevap verenler ve cevap vermeyenlerin toplami) $\% 13$ 'tür. Bu hastalıksız sağkalımı olan üç hastada $22.6 \pm 8.3$ hafta boyunca trombosit 
değerinde cevapsızlık derecesine kadar düşme olmuyor.

H.Pylori eradike edilen hastalardan 9 erkeğin biri ve 10 kadının ikisi tedaviye cevaplıydı. Tedaviye cevaplı hastaların tamamı 65 yaş altındaydı. Tedaviye cevaplı hastalar 45.6 16.2 yaş (aralık 27-57), tedaviye cevapsızlar $38 \pm 10.2$ yaşındaydı (aralık 19-57). Tedaviye cevaplı hastalar, tedaviye cevapsızlardan istatistiksel olarak anlamlı olacak kadar yaşlı değillerdi $(\mathrm{p}=0.267)$.

Bazal trombosit sayısı, tedaviye cevaplı hastalarda 40.6 27.1 bin (aralık 2472 ), tedaviye cevapsız hastalarda $45.1 \pm 13.0$ bindi (aralık 20-61 bin), aralarında istatistiksel olarak anlamlı fark yoktu $(\mathrm{p}=0.647)$.

Hastalık süresi, tedaviye cevaplı hastalarda $120 \pm 109$ ay (aralık 24-240 ay), tedaviye cevapsız hastalarda $49 \pm 48$ aydı (aralık 12-180 ay) ve aralarında istatistiksel olarak anlamlı fark yoktu $(\mathrm{p}=0.071) . H$. Pylori eradikasyonu ile trombosit cevabı olanlar ile olmayanların yaş, hastalık süresi, bazal trombosit sayısı arasındaki ilişki Tablo 3'de sunulmuştur.

Eradikasyondan sonra, birinci hastada 8 hafta sonra, ikinci hastada 32 hafta sonra, daha önce trombosit cevabı görülmüş olmasına rağmen, iki hastada trombosit cevabı cevapsızlığa geriledi. Relaps gelişen bu iki hastada Üre Nefes Testi (UBT) ile H.Pylori'nin halen negatif olduğu gösterildi.

H.Pylori eradikasyonu başarısız olan dört hastadan dördünde takiplerinde trombosit sayısı başlangıçtaki değerlere yakın kaldı. Hiçbir hastada, herhangi bir ek tedavi vermeden, trombosit sayısında başlangıca göre cevap denebilecek düzeyde artış elde edilmedi.

Daha önce splenektomi veya herhangi bir immünsupresif ile tedavi görenlerde cevap oranı $15^{\prime}$ de üçtür (\%20). Daha önce tedavi görmeyenlerde cevap oranı dörtte sıfırdır.

15 hastalık H.Pylori negatif ITP'li hastadan 11'inde herhangi bir tedavi uygulanmadı. bir hastada splenektomi ile tedaviden 32 hafta sonra trombosit cevabı 130 bin oldu. iki hasta steroid tedavisi gerektirdi, bir hasta IVİG tedavisi gerektirdi ancak tedavi bitiminden sonra trombosit düzeyleri tekrar 80 binin altına düştü. H.Pylori negatif herhangi bir tedavi gerektirmeyen hastalardan hiçbirinde cevap denebilecek düzeyde trombosit artışı görülmedi.

Tablo 3. Helicobacter Pylori Eradikasyonu ile Trombosit Cevabı Olanlar ile Olmayanların Yaş, Hastalık Süresi, Bazal Trombosit Sayısı Arasındaki İlișki

\begin{tabular}{lccc}
\hline & $\begin{array}{c}\text { Eradikasyonla trombosit } \\
\text { cevabı olanlar } \\
\mathrm{n}=3\end{array}$ & $\begin{array}{c}\text { Eradikasyonla trombosit } \\
\text { cevabı olmayanlar }\end{array}$ & $\mathrm{p}$ \\
& Ort \pm S.S & $\mathrm{n}=16$ & \\
Yaş & $45.6 \pm 16.2$ & Ort \pm S.S & \\
Hastalık süresi (ay) & $120.0 \pm 109.9$ & $38.3 \pm 8.9$ & 0.267 \\
Bazal PLT sayısı (bin/ml) & $40.6 \pm 27.1$ & $49.5 \pm 47.1$ & 0.071 \\
\hline
\end{tabular}

\section{Tartışma}

ITP, etyopatogenezi tam olarak bilinmeyen ancak immün sistem bozukluğu zemininde gelișen, trombosit düşüklügü, ciddi klinik düzeyde kanama bulguları olabilen, bazen akut, bazen kronik seyirli bir hastalıktır.

H.Pylori için tanısal testler endoskopi gerektirip gerektirmediğine göre invaziv ve noninvaziv olarak ayrilır. Teknikler direkt (kültür, organizmanın 
mikroskopik olarak gösterilmesi) veya indirekt (üreaz kullanarak veya hastalık belirleyici antikor cevabı ile) olabilir. Testlerin seçimi kesin test sonuçlarını etkileyebilecek; maliyet, uygulanabilirlik, klinik durum, enfeksiyonun popülasyon prevelansı, test öncesi enfeksiyon olasılığı, ppi ve antibiyotik kullanımı gibi faktörlere bağlıdır. H.Pylori tanısı için çeşitli noninvaziv testler kullanılmaktadır. Bunlar, üre nefes testi (UBT), dışkı antijen testi ve seroloji testidir. UBT'nin sensitivitesi ve spesifitesi sırasıyla yaklaşık \%88-95 ve \%95-100 dür. ${ }^{7} \mathrm{Bu}$ nedenle yanlış pozitif sonuçlar nadirdir.

H.Pylori'nin gastroduodenal hastalıklar ve kanserlerin etyolojisinde önemi kanıtlanmış, otoimmün hastalıklar ile ilişkileri yönüyle de birçok çalışma yayınlanmıștır. $\mathrm{Bu}$ otoimmün hastalıklardan biri de ITP'dir. ITP'ye neden olduğu düşünülen de bazı H.Pylori suşlarında bulunan cagA genidir. ${ }^{8}$

Giovanni ve arkadaşlarının ${ }^{8}$ yaptığ çalışmada H.Pylori'nin ITP patogenezi ile ilgili birinci teori; CagA'nın epitelyal hücrelerdeki yaptığı değisşiklikler, plazminojen aktivatör inhibitör-1 ekpresyon artışını içerir, bu da moleküler benzerliğe toleransın kaybolmasına yol açar. CagA ile trombosit antijenlerinin benzerliğine karşı immünolojik bir ortam oluşturulur ve ITP oluşması kolaylaştırılır. İkinci teori; bazı H.Pylori suşlarının trombosit aktivasyonunu ve agregasyonunu indükleyerek gastrik mukozal inflamasyona ve sistemik hastalıklara sebep olabileceğidir. ${ }^{8}$

Bizim çalışmamızda H.Pylori eradike edilen ITP'li hastalarda \%15.7 trombosit

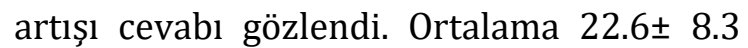
hafta (aralık 16-32 hafta) boyunca bu cevap devam etti. Ancak bu hastaların dişında iki hastada daha eradikasyon tedavisinden sonra cevap görülmesine rağmen sonrasında trombosit sayısı cevapsızlığa geriledi. $\mathrm{Bu}$ hastalarda trombosit sayısının cevapsızlığa gerilemesinin nedeninin H.Pylori relapsından kaynaklanmadığ hastalara UBT'yi (Üre Nefes Testi) tekrarlayıp H.Pylori'nin negatif olduğu gösterilerek kanttlandı. $\mathrm{Bu}$ da ITP etyopatogenezinde başka faktörlerin de önemli olduğunu göstermiştir.

Michel ve arkadaşlarının ${ }^{9}$ yaptığ çalışmada H.Pylori'nin ITP'li hastalarda genel popülasyonla benzer oranda görülmesi, ancak H.Pylori eradike edilince belirgin trombosit artışı cevabı gözlenmesi, H.Pylori'nin ITP başlangıcından ziyade kronikleşmesinde daha önemli olduğunu düşündürebilir. Bizim çalışmamızda da H.Pylori enfeksiyonu ITP'li hastalar ve sağlıklı popülasyonla benzer oranda görülmüştür. $\mathrm{Bu}$ bulgularla H.Pylori'nin hastalığın başlamasında muhtemel etken ancak tek başına güçlü bir etken olmadığı, hastalığın kronikleşmesinde daha etkin olduğu düşünülebilir.

Giovanni ve arkadaşlarının ${ }^{10}$ yaptığ 1 34 erişkin ITP'li hastanın ortalama 60 ay takip edildiği bir İtalyan çalışmasında cevap oranı \%68 bulunmuş. Japonya'dan yapılan çalışmaların ağırlıklı olduğu bir metaanalizde bu oran erişkinlerde \%50 bulunmuştur ancak bu metaanalizde değişik seriler arasında oldukça büyük farklılıklar mevcuttur. Stasi ve arkadaşlarının ${ }^{11}$ yaptığ metaanaliz çalışmasında genelde H.Pylori enfeksiyon oranı yüksek olan ülkelerde, ITP'de eradikasyon tedavisine cevap oranı da yüksek bulunmuştur. Bu teori ile ilgili patogenez; cagA geni pozitif H.Pylori'lerin bulunması ile ilişkilendirilmiştir. Bu genin ITP için patogenik aday olduğu iki moleküler çalışma ile gösterildi. ${ }^{6} \mathrm{Bu}$ çalışmalarda cagA'nın trombosit antijenlerine benzerliği gösterildi ayrıca H.Pylori eradikasyonu ile anti-cagA antikorunun kaybolduğu ve trombosit sayısının arttığı gösterilerek desteklendi. ${ }^{6}$ $\mathrm{Bu}$ teorinin aksine, ülkemizde H.Pylori yüksek oranda görülmesine rağmen, çalışmamızda H.Pylori eradikasyonuna cevap yukarıda bahsedilen kadar yüksek bulunmamıştır.

H.Pylori'nin gastrik ülser, duodenal ülser, gastrik kanser, Mukoza İlişkili Lenfoid Doku (MALT) Lenfoma'nın patogenezinde rol oynadığı, mekanizması tam olarak bilinmese de, kesin olarak bilinmektedir. H.Pylori ile birçok otoimmün hastalığın (pernisiyöz anemi, Romatoid Artrit, İmmün Trombositik Purpura gibi) beraberliği ile 
ilgili literatürde yapılmış birçok çalışma mevcuttur. H.Pylori'yi bu kadar çok hastalıkla ilişkilendirmek başlangıçta mantıksızmış gibi görünse de şimdiye kadarki bilgilerimizden H.Pylori'nin neden olduğu bilinen duodenal ülser, özellikle de MALT Lenfoma gibi hastalıkların sadece H.Pylori'yi eradike ederek tamamen iyileşebileceğini bilmekteyiz. 0 zaman Lenfoid Sistem üzerine bu derece etkili bir bakterinin, immünolojik bu hastalıklarla ilişkisi kesin yok demek çok zor görünmektedir.

Ciddi trombositopenisi ( $<30$ bin $)$ olan hastalarda cevap oranı \%50'dir, bu oran trombosit sayısı 30-50 bin olan ve 5080 bin olan hastalara göre belirgin olarak daha fazladir. Ciddi trombositopenilerdeki bu cevap oranı, klinik takipleri daha problemli olması ve daha sık immünsupresif tedavi gerektirmesi nedeni ile hastalık gidişatı üzerine daha etkilidir. Ciddi trombositopenili hastalarm H.Pylori eradikasyonu ile tedavi edilebildiğinin gösterilmesi maliyet-etkinlik analizi açısından da önemlidir. Başlangıçta H.Pylori durumu bilinmeyen 100 ITP'li hastadan birinin bile H.Pylori eradikasyonu ile tedavi edilmesi, bu hastaya daha sonra IVIG veya Ritüksimab tedavisi uygulanabileceğini düşünürsek sadece bir hastanın bile maliyeti 100 hastanın H.Pylori açısından taranması ve tedavisinin masrafinı karşılayacaktır.

$\mathrm{Bu}$ çalışmada verilen bulgularla, ITP'li hastalar H.Pylori için rutin taranmalı mı sorusuna hasta sayısı ve istatistiksel kısıtlamadan dolayı net cevap vermek mümkün değildir. Literatürdeki benzer çalışmalarla karşılaştırdığımızda ve beraber değerlendirdiğimizde, daha düşük maliyetli olabileceği, invaziv olmayan teșhis yöntemleri içinde yüksek duyarlılık ve özgüllügü olması, standart ITP tedavisi ile karşılaştırıldığında düşük toksisite profiline sahip olması gibi özelliklerini de dikkate alırsak bu soruya olumlu cevap verme ihtimali artabilir.

\section{Kaynaklar}

1. Arnold DM, Bernotas A, Nazi I, Stasi R, Kuwana M, Liu Y, Kelton JG, Crowther MA. Trombosit count response to $H$. pylori treatment in patients with immune thrombocytopenic purpura with and without H. pylori infection: A systematic review. Haematologica 2009;94:850

2. Cines DB, Blanchette VS. Immune thrombocytopenic purpura. $N$ Engl J Med 2002; 346:995.

3. Michel M, Lee K, Piette JC, Fromont $P$, Schaeffer A, Bierling P, Godeau B. Trombosit autoantibodies and lupus-associated thrombocytopenia. $\mathrm{Br} \quad \mathrm{J}$ Haematol 2002;119:354.

4. Kuwana, M, Kaburaki, J, Okazaki, Y, Miyazaki H, Ikeda Y. Two types of autoantibody-mediated thrombocytopenia in patients with systemic lupus erythematosus. Rheumatology (Oxford) 2006;45:851.

5. Nugent D, McMillan R, Nichol JL, Slichter SJ. Pathogenesis of chronic immune thrombocytopenia: increased trombosit destruction and/or decreased trombosit production. BrJ Haematol 2009;146:585.

6. Rodeghiero F, Stasi R, Gernsheimer T, Michel M, Provan D, Arnold DM, Bussel JB, Cines DB, Chong BH, Cooper N, Godeau B, Lechner K, Mazzucconi MG, McMillan R, Sanz MA, Imbach P, Blanchette V, Kühne T, Ruggeri M, George JN. Standardization of terminology, definitions and outcome criteria in immune thrombocytopenic purpura of adults and children: report from an international working group. Blood. 2009;113(11):2386.

7. Howden CW ve Hunt RH. Guidelines for the management of Helicobacter pylori infection. Ad Hoc Committee on Practice Parameters of the American College of Gastroenterology. Am J Gastroenterol. 1998;93(12):2330.

8. Emilia G, Luppi M, Zucchini P, Morselli M, Potenza L, Forghieri F, Volzone F, Jovic G, Leonardi G, Donelli A, Torelli G. Helicobacter pylori infection and chronic immune thrombocytopenic purpura: long-term results of bacterium eradication and 
association with bacterium virulence profiles. Blood, 2007 Dec 1;110(12):383341.

9. Michel M, Cooper N, Jean C, Frissora C, Bussel JB. Does Helicobater pylori initiate or perpetuate immune thrombocytopenic purpura?. Blood, 1 February 2004; Vol. 103, No. 3, pp. 890-896.

10. Emilia G, Longo G, Luppi M, Gandini G, Morselli M, Ferrara L, Amarri S, Cagossi K, Torelli G. Helicobacter pylori eradication can induce trombosit recovery in idiopathic thrombocytopenic purpura. Blood, 1 February 2001; Vol. 97, No. 3, pp. 812-814

11. Stasi R, Sarpatwari A, Segal JB, Osborn J, Evangelista ML, Cooper N, Provan D, Newland A, Amadori S , Bussel JB . Effects of eradication of Helicobacter pylori infection in patients with immune thrombocytopenic purpura: a systematic review. Blood 5 Feb 2009; Vol 113, No:6:1231-1240 